\title{
Effect of Laser Surface Treatment on Transition Temperature of Ni/Ti SMAS
}

\author{
Ekbal Mohammed Saeed Salih*, Baraa H. Al Khaqani
}

University of Babylon, Metallurgy Department, College of Materials Engineering, Babylon, Hillah 51001, Iraq

Corresponding Author Email: Mat.ekbal.moh@uobabylon.edu.iq

https://doi.org/10.18280/ijht.390123

Received: 3 March 2020

Accepted: 16 December 2020

\section{Keywords: \\ NiTi SMAs, transformation temp., biocompatibility, ion relies, surface} treatment, laser treatment

\begin{abstract}
It is well established that SMAs have a great important as: engineering and biomaterial applications, because of unique properties that had as well as, good biocompatibility. however, duo to its possible corrosion in physiological solution, dissolution of toxic $\mathrm{Ni}$ might be happening. Several studies have been carried out to improve the stability of the passive protective film of $\mathrm{TiO}_{2}$ and prevent the Ni ion relies out of NiTi. Surface treatment is one of these methods or techniques such as, ion implantation, plasma electro polishing, passivation, ultra-sonic treatment and laser treatment, most of these treatments are effects on transition temperatures $\left(A_{s}, A_{f}, M_{s}, M_{f}\right)$. Change of these temps. will affected the normal use especially in human body, so keeping these temps. within the range of the human body is of main requirements to Evaluation the efficiency of any treatment. In this study (55 wt $\% \mathrm{Ni}, 45 \mathrm{wt} \% \mathrm{Ti}$ ) SMAs has been prepared by (PM), compacted at $850 \mathrm{MPa}$ and sintered. Laser pulses deposition technique at $(1064,532) \mathrm{nm}$ at different energy $(2$, $2.3,2.7) \mathrm{J}$. At power (200) wat in constant duration time ( $2 \mathrm{~ns}$ ) has been used to modify surface by continuous stricks (side by side) to study mechanical, corrosion properties and how laser pulses effects on transition temp. All results confirmed that there is a positive effect on properties, \% improving in hardness with respect to reference sample are (145, $132.8,123.8)$ and $(180.9,169.5,152.3)$ at 1064,532 wave length respectively. Improvement in Ni relies are equal to $(52,38) \%$ with respect to reference sample. On the other hand, there are slight positive change on transition martensitic transformation, thermal hysteries $\left(A_{s}-M_{s}\right)$ there are reduction in degress from $50^{\circ} \mathrm{C}$ (untreated sample) to $(36.9,33.6)^{\circ} \mathrm{C}$, while for martensitic transformation $\left(A_{f}-M_{f}\right)$ the degress are decrease from $(65)^{\circ} \mathrm{C}$ for untreated sample to $(57.5,51.7)^{\circ} \mathrm{C}$ wave length respectively.
\end{abstract}

\section{INTRODUCTION}

As it's known, shape memory alloys (SMAs) are of great technical importance for many reasons, its corrosion resistance, good mechanical properties and good biocompatibility [1]. These alloys are metals, they exhibit unique characteristic properties (super elasticity, shape memory effect). These unique properties take place throw solid state change, due to change in surrounding conditions [2], e.g.: change in temperatures, concentration, moisture degree, $\mathrm{PH}$ and even electrical and magnetic fields. It has the ability to respond to the surrounding environments in dependently and intelligently so they are unique materials in their properties. These alloys are used as a means of control, sensors, actuators, damping, robot, vibrations suppression, biomaterials (bones), reinforcement for arteries and veins, dental wires ...etc. [3-6].

These smart alloys remember their original shape even after server deformation, this deformation occur at low temperature (soft phase martensite), but when environment change (e.g.: small change in temperature) it spontaneously returns to its original unformed shape this change of behavior can be used in a wide variety of applications, mechanical, medical, engineering, aerospace .... There are many alloys joins to this smart alloy [7], but the most popular on the commercial level are Ni/Ti alloys, and cu-base alloy. Ni/Ti alloys exhibit good biocompatibility, mechanical properties and good corrosion resistance $[8,9]$, but this alloy suffering from major problem, which is the (toxic nickel ions release) especially when use as a biomaterial (in human body) [10,11], it is known that human body tissues contain of oxygen, protein, hydroxides, chlorides and water.

Many studies have been conducted to enhance and strengthen properties (mechanical, chemical) and to increase biocompatibility [12-14] and their effects on transition temperature. Keeping the transformation temperature within the range of human body is the main requirements that assess the efficiency of any mechanism used [15].

In this study laser surface treatment/laser pulsed type (Nd:YAG HAN*S PB80 laser) used to improve and enhance surface characteristic of $(55 \% \mathrm{Ni}, 45 \% \mathrm{Ti})$ wt. by treated surface with continuous pulses (side by side), with wave length $(1064,532) \mathrm{nm}$. Several tests have been tested to study the effect laser pulses on mechanical (hardness) and chemical (ion release of nickel) and how transition temperatures are change.

\section{EXPERIMENTAL WORK}

Table 1. Solar panel specification

\begin{tabular}{ccc}
\hline Powder & Purity \% & Partical size $\mu \mathrm{m}$ \\
\hline $\mathrm{Ni}$ & 99.98 & $20-35$ \\
$\mathrm{Ti}$ & 99.99 & $25-40$ \\
\hline
\end{tabular}


Table 2. Represented laser pulse depositions conditions

\begin{tabular}{cccccccccc}
\hline \multirow{2}{*}{ Samples } & \multicolumn{4}{c}{ Laser wave length 1064 nm } & & \multicolumn{3}{c}{ Laser wave length 532 nm } \\
& Energy J & Frequency Hz & Power W & $\begin{array}{c}\text { duration time } \\
\text { ns }\end{array}$ & Samples & Energy J & Frequency Hz & Power W & duration time \\
ns
\end{tabular}

Table 1 represented the particle size $(\mu \mathrm{m})$ and purity $\%$ of NiTi powder that used in this study.

Particle size analysis has been tested by analyzer laser particle size better size (2000) which based on laser diffraction method is formed of an irradiation optical system for irradiating laser beam to particles, the test was carried out by a half gram $(0.5 \mathrm{~g})$ of each powders (NiTi) and mixed with a glycerin as a medium (suspended). Reference samples was perpetrated (45 wt. \% Ti- 55 wt.\% Ni) using a sensitive balance (4 digits), total weight of each sample was (8 gram), after mixing ( $3 \mathrm{hr}$.) a hydraulic press machine was used to compacted powder under $(850 \mathrm{MPa})$, then samples of $(4 \mathrm{~mm})$ high and $(3 \mathrm{~mm})$ diameter were prepared. Figure 1 represented sintering process using vacuum furnace $\left(10^{-4}\right.$ torr $)$, heating rate was $10^{\circ} \mathrm{C} / \mathrm{min}$.

All sintered samples are perpetrated for subsequent testing which include (grinding with different degrees of emery paper $(600,800,2500) \mu \mathrm{m}$, then a fine cloth was used with alumina of $(0.1) \mu \mathrm{m}$ particle size for polishing, after that washing with distillate washer and drying. A continuous laser deposition type Nd:yAG was used to strike surface samples continuously (side by side) at different condition as shown in Table 2.

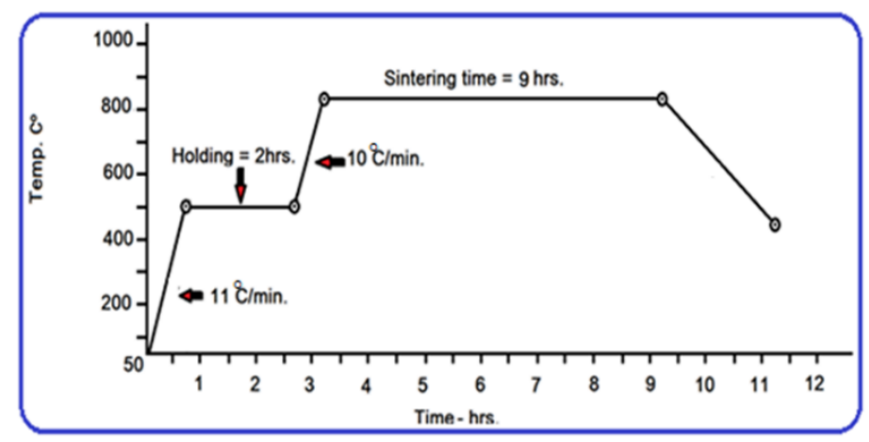

Figure 1. Sintering process

\section{BASIC EQUATIONS}

\subsection{XRD}

XRD patterns for all samples (reference, treated samples) has been conducted using X-ray diffraction type Philips (pw 3710 ), the target used was $\mathrm{cu} K \mathrm{cu}=1.542 \mathrm{~A}^{\circ}$. All results confirmed the presence of $\mathrm{Ni} \mathrm{Ti}$ phase. In reference sample two phases (B19 Martensite phase and B2 austenite phase) as well as $\mathrm{NiTi}_{2}, \mathrm{TiNi}_{3}$ (Figure 2).

On other hand, treated sample patterns show the presence of $\mathrm{Ti}_{2} \mathrm{Ni}$ and $\mathrm{TiO}_{2}$. This means a rich outer layer of $\mathrm{TiO}_{2}$ was formed as a result of a laser treatment, also peak intensity of $\mathrm{TiO}_{2}$ increase as energy increase for the same wave length Figures 3, 4 and also as wave length became shorter (532) nm (high energy) Figures 5, 6.

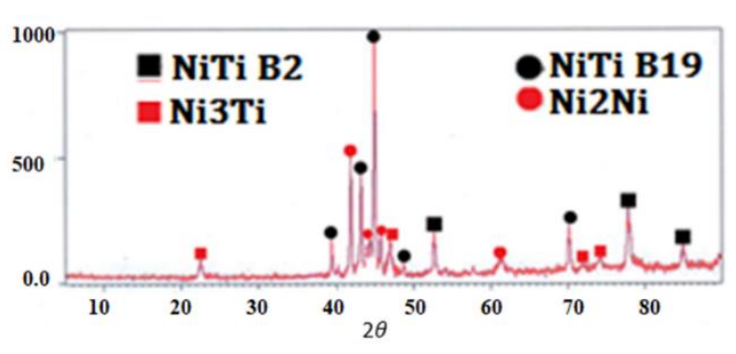

Figure 2. XRD for reference samples

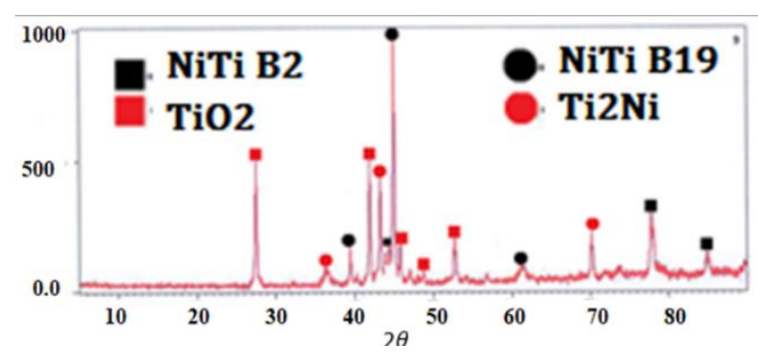

Figure 3. XRD For A sample at 1064 nm

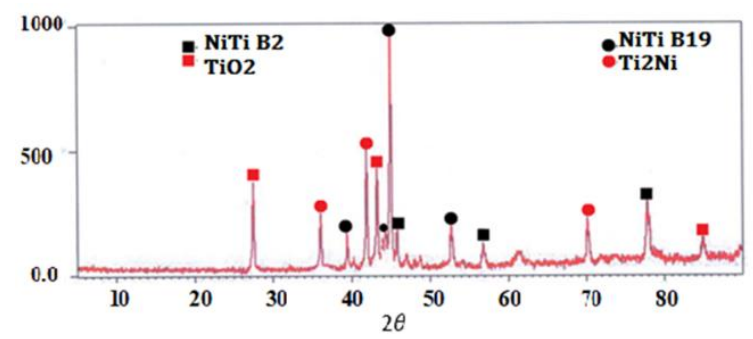

Figure 4. $\mathrm{XRD}$ for $\mathrm{C}$ sample at $1064 \mathrm{~nm}$

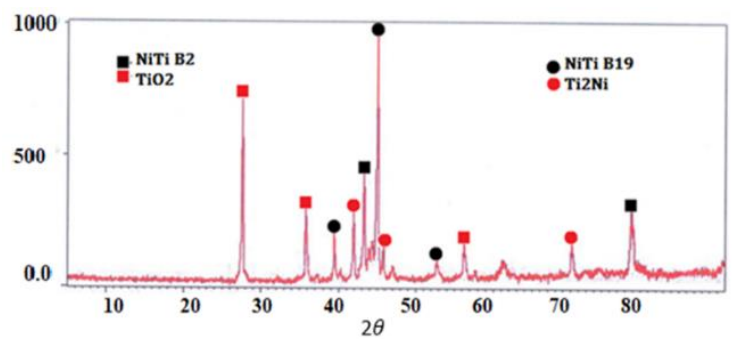

Figure 5. XRD for AA sample at $532 \mathrm{~nm}$

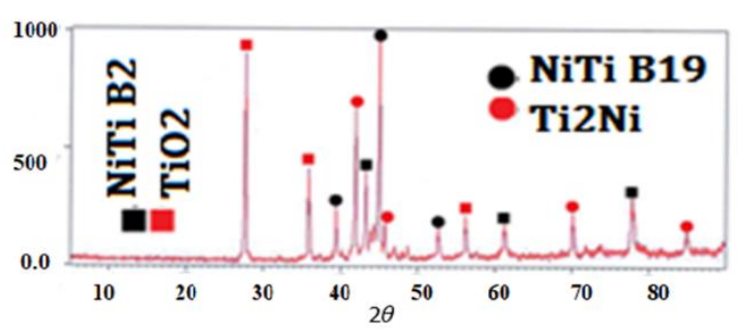

Figure 6. XRD for sample $\mathrm{CC}$ at $532 \mathrm{~nm}$ 
Hardness test was measured for all samples, values are proved a significant increase for treated samples with respect to reference sample $(210 \mathrm{HV})$ as shown in Table 3.

Table 3. Hardness for all samples

\begin{tabular}{ccc}
\hline Samples & HV & \% Improvement \\
\hline Reference & 210 & - \\
A & 260 & 123.8 \\
B & 279 & 132.8 \\
C & 305 & 145 \\
AA & 320 & 152.3 \\
BB & 356 & 169.5 \\
CC & 380 & 180.9 \\
\hline
\end{tabular}

Three results can be conducted from Table 3 , first as mention previously, there are an increase in hardness for all samples treated with laser. Second there are an increase in hardness value as energy increases at constant wave length, third the hardness increases at constant energy with shorter wave length $(532 \mathrm{~nm})$ although all other conditions (powder, duration time, frequency) are constant. Figure 7 shows hardness value for all treated samples with respect to Ref. sample.

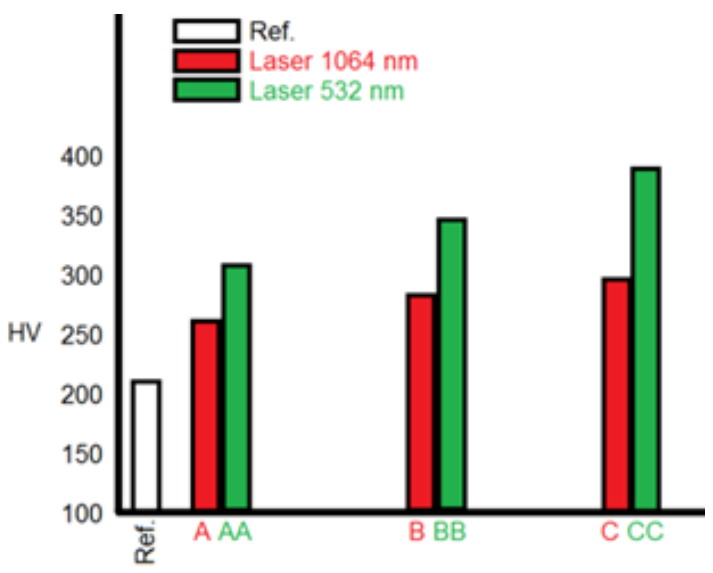

Figure 7. Hardness for all treated, untreated samples

\subsection{Transformation temperature (DSC)}

Figures 8, 9, 10, 11 and Table 4 represented the transition temperature of all samples treated and untreated sample) at different condition. This test has been carried out by differential scanning calorie meter (DSC). In this test (5 gram) of each sample tested at a scan rate of $5^{\circ} \mathrm{C} / \mathrm{min}$. range temperature was $(-100-200)^{\circ} \mathrm{C}$. From Table 4 there are changes in degrees of transformation temp., but this change can be described as a slide change.

Table 4. Transformation temperature for all samples (untreated, treated samples) at different laser conditions

\begin{tabular}{|c|c|c|c|c|c|c|}
\hline \multirow[b]{2}{*}{ Samples } & \multicolumn{4}{|c|}{ Transformation Tem. } & \multirow{2}{*}{$\begin{array}{c}A_{f^{-}} \\
M_{s} \\
{ }^{\circ} \mathrm{C}\end{array}$} & \multirow{2}{*}{$\begin{array}{c}A_{f}- \\
M_{f}{ }^{\circ} \mathrm{C}\end{array}$} \\
\hline & $\mathrm{Ms}{ }^{\circ} \mathrm{C}$ & $\mathrm{Mf}^{\circ} \mathrm{C}$ & $\mathrm{As}^{\circ} \mathrm{C}$ & $\mathrm{Af}^{\circ} \mathrm{C}$ & & \\
\hline Ref. & 60 & 45 & 75 & 110 & 50 & 65 \\
\hline A & 63 & 42 & 73 & 101 & 38 & 59 \\
\hline $\mathrm{C}$ & 63.6 & 43 & 74.8 & 100.5 & 36.9 & 57.5 \\
\hline AA & 65.4 & 48.1 & 72.8 & 99.6 & 34.2 & 51.5 \\
\hline $\mathrm{CC}$ & 65.4 & 47.3 & 70 & 99 & 33.6 & 51.7 \\
\hline
\end{tabular}

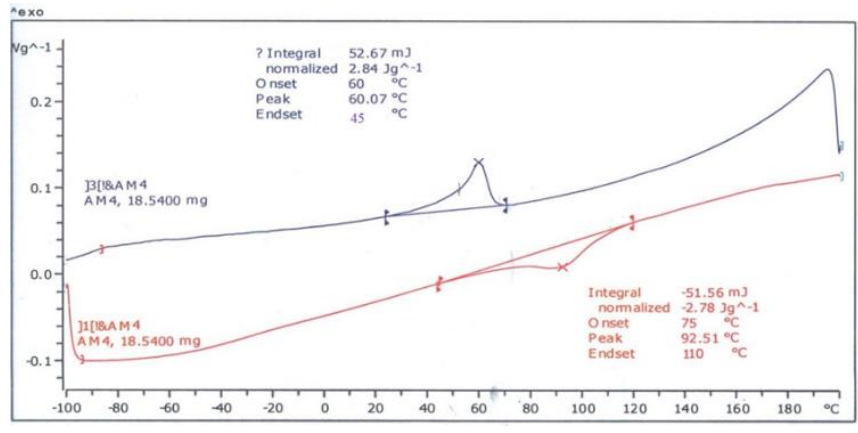

Figure 8. DSC for base sample

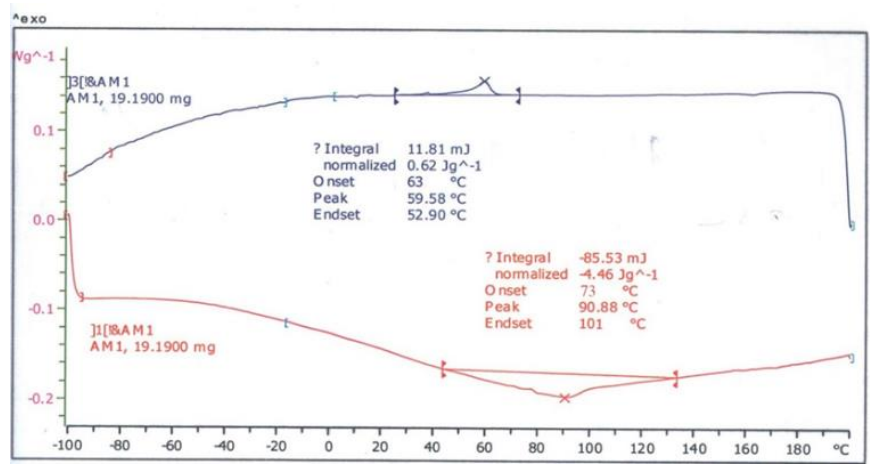

Figure 9. DSC for A sample

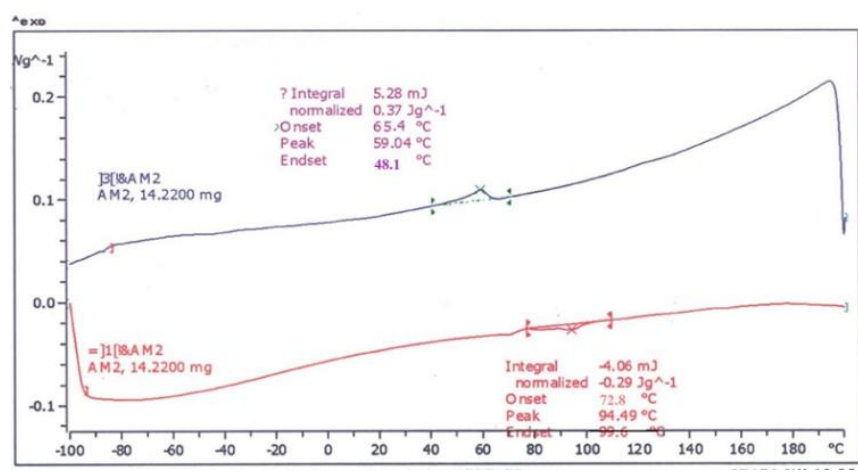

Figure 10. DSC for AA sample

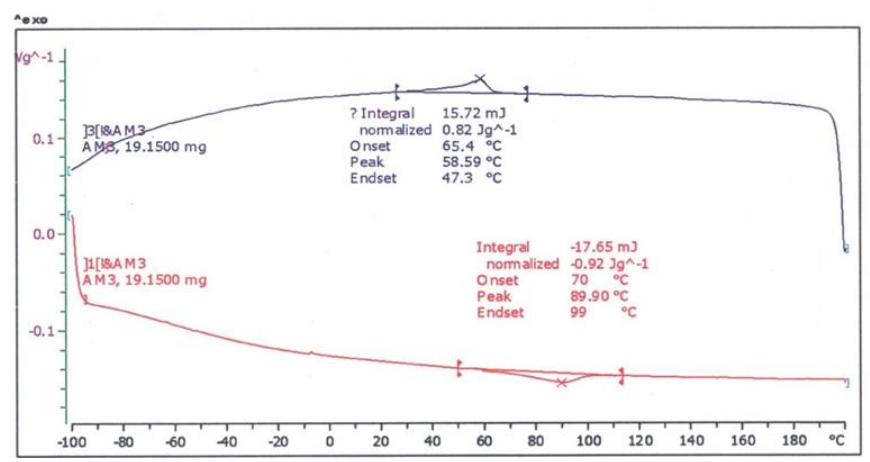

Figure 11. DSC for CC sample

\subsection{Nickel ion release}

This test also is one of the most important tests, which use to evaluated efficiency of any treated used for these alloys because increasing in nickel level in human body causes an allergic, toxic effect. All samples tests by using atomic 
absorption spectrometry (AAS) in Honks solution at $37^{\circ} \mathrm{C}$ for (3 weeks), results shown in Table 5 and Figure 12.

Table 5. Ni - ion release for all samples

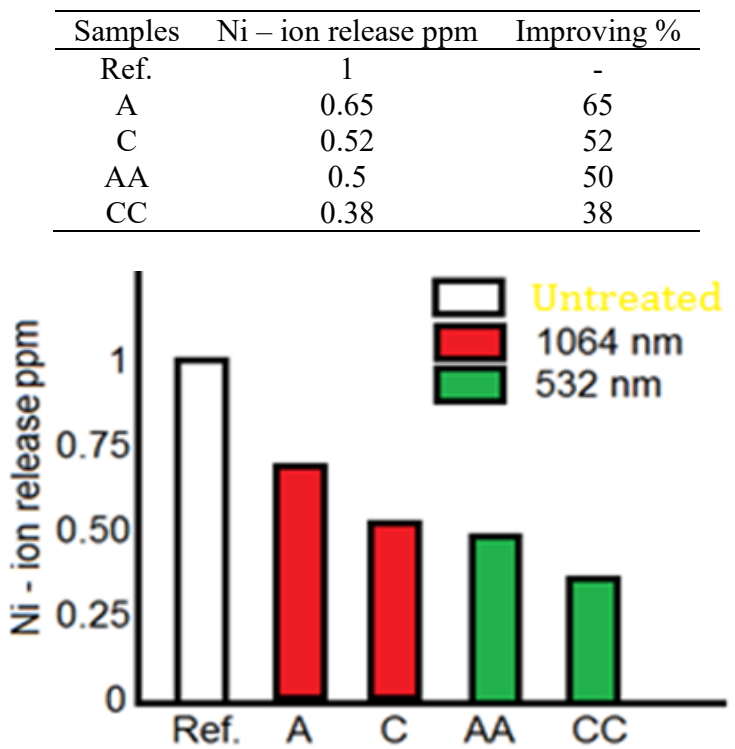

Figure 12. Comparison in Ni release for all samples (treated and untreated)

\subsection{Corrosion test}

Table 6, Figure 13 current density represented current density of all samples (untreated and treated samples) at different conditions.

Table 6. Current density of all samples

\begin{tabular}{cccc}
\hline Samples & $i_{c o} \mu \mathrm{A}$ & Current density $\mu \mathrm{A} / \mathrm{cm}^{2}$ & Improving $\%$ \\
\hline Ref. & 20.63 & 292 & - \\
A & 11.71 & 165.74 & 56.76 \\
B & 5.54 & 77.14 & 26.41 \\
C & 3.62 & 51.23 & 17.54 \\
AA & 3.13 & 44.3 & 15.17 \\
BB & 2.71 & 38.35 & 13.13 \\
CC & 1.11 & 15.71 & 5.38 \\
\hline
\end{tabular}

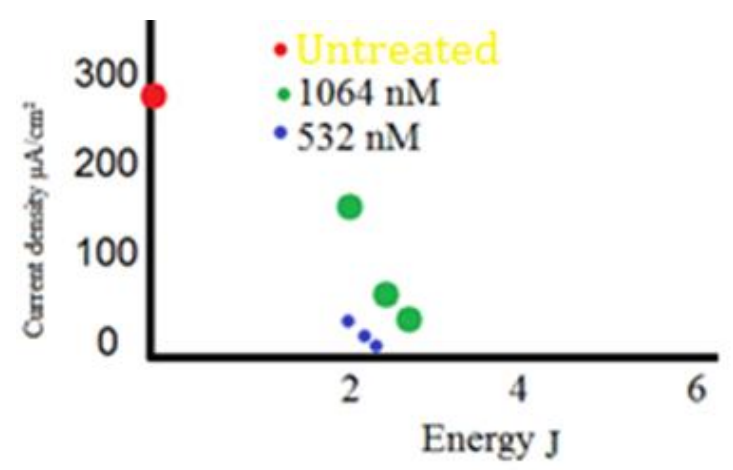

Figure 13. DSC for a sample

\section{DISCUSSIONS}

Figures 2 to 6 confirmed the presence of NiTi phase (SMA). In Figures 2 [reference sample] there are two phases (B19 Martensite phase and B2 austenite phase) as well as $\mathrm{NiTi}_{2}$,
$\mathrm{TiNi}_{3}$. On the other hand, Figures 3, 4, 5, 6 show the presence of $\mathrm{NiTi}_{2}, \mathrm{TiO}_{2}$ as well as (B19, B2). This means rich outer layer of $\left(\mathrm{TiO}_{2}\right)$ formed as a result of laser treatment. Also, peck intensity increases as; firstly, energy of wave length laser increase Figures 3, 4 and Figures 5, 6, secondly wave length become shorter, Figures 3, 6 [13].

Hardness values also confirmed the effect of laser surface treatment as a positive effect. All hardness increase compare to reference ,the higher hardness of laser treatment sample is $(380 \mathrm{HV})$ compare to $(210 \mathrm{HV})$ reference sample ,there is an improving (180.9\%) with respect to reference sample, all these effects can be attributed to the energy of laser as following: first at constant wave length but higher energy, second constant energy but shorter wave length, i.e. the narrow beam with (higher energy or shorter wave length) will strike surface layer producing a small molten regions followed by rapid solidification (self-quenching )resulting in a very fine grain in comparation with reference sample. Also, treatment result a compressive stress which leads to amorphization structure and dislocation, all these are responsible for the hardness increase [14].

According to Table 5,we can concluded that laser surface treatment have a fair effects on transformation temperatures even at high or low energy of the same wave length or even at short wave length i.e. thermal hysterias $\left(A_{f}-M_{S}\right)$ it was equal to $50^{\circ} \mathrm{C}$ for reference sample while it reach to $(38-36.9)^{\circ} \mathrm{C}$ at $1064 \mathrm{~nm}$ and $(34.2-33.6)^{\circ} \mathrm{C}$ for $(532 \mathrm{~nm})$ on the other hand martensitic transformation $\left(A_{f}-M_{f}\right)$ it was $65^{\circ} \mathrm{C}$ for reference sample, and equal to $(59 \& 57.5)^{\circ} \mathrm{C}$ for $1064 \mathrm{~nm}$ and equal to $(51.5 \& 51.7)$ for $532 \mathrm{~nm}$, as show in Figure 14 and Figure 15.

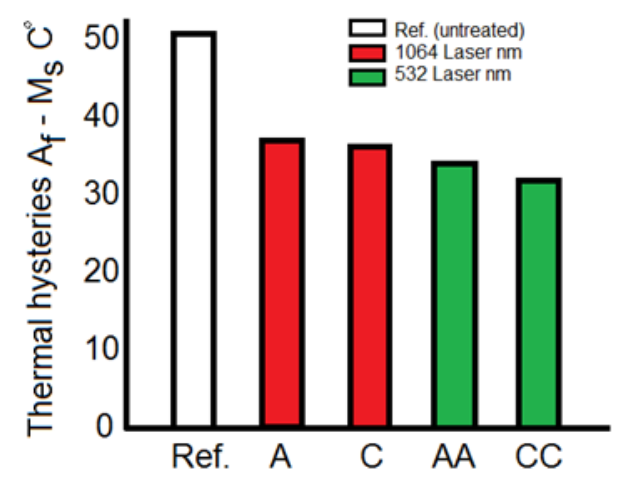

Figure 14. Comparison in thermal hysteries for untreated samples

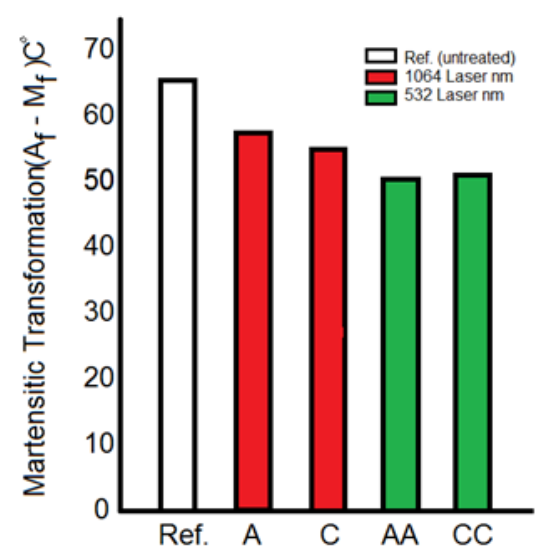

Figure 15. Comparison in martensitic transformation for treated, untreated samples 
From these Figures, we can concluded that "laser shock" which known as a "shoot peening" produce few residual compressive stress which have a minimum change effects in the bulk material ,this is agree with other studies [16], on other hand ,a great decreases take place in nickel ion release, it reach to $38 \%$ with respect to reference sample for short wave length $(532 \mathrm{~nm})$ and $52 \%$ with respect to reference sample with long wave length (1064 nm).this may be explain due to first ,formation of $\left(\mathrm{TiO}_{2}\right)$ on the surface ,titanium oxide are known as a protective layer (best),prevent or hinder the diffusion of $\mathrm{Ni}$ ion $[16,17]$ as well as $\left(\mathrm{TiO}_{2}\right)$ describe as a protective, an adhesive, rehealing, so that oxide have a great ability to prevent or decreases nickel ion release .Secondly, high temperatures during surface treatment produce narrow melting layer followed by rapid cooling, encourage the great generation of fine grains with high density of grain boundary ,this will accelerated forming of protective layers $\left(\mathrm{TiO}_{2}\right)$ and prevent out ward diffusion of $\mathrm{Ni}[18,19]$.

Corrosion test are also one of the most important factored for SMAs especially when you as bio material. This test has been currented out by Tafel extrapolation method in artificial saliva at $37^{\circ} \mathrm{C}$ for all samples, results are represented in Table 6 and Figure 14, which shows the improvements in corrosion rate with respect to reference sample. current density for untreated sample was $292 \mu \mathrm{A} / \mathrm{cm}^{2}$ this value decreases when laser treatment take place, improving on corrosion density was equal to $(56,26,17)$ and $(15,13,5)$ with respect to reference sample at wave length (1064) $\mathrm{nm}$ respectively. This behavior attributed to formation of protective well -adherent corrosion resistant layer of $\left(\mathrm{TiO}_{2}\right)$ [20, 21]. Ti is noble than (Ni) so that, the oxide is accepted to be completely of $\left(\mathrm{TiO}_{2}\right)$. On the other hand, at shorter wave length $(532 \mathrm{~nm})$ will decreases the current density at same conditions this means that more heat will transfer to the substrate which in turn enhance the building rate of the protective oxide layer [22].

\section{CONCLUSIONS}

There are un enhancement in properties (mechanical, chemical and even transition temperature) increasing in hardness reach to $(145,180) \%$ at higher energy, and shorter wave length with respect to reference sample. Also degreases $\mathrm{Ni}$ ion release and current density $(52,38$ and 17,5$) \%$ with respect to reference sample on the other hand, there are positive slide effect (change in transition temperature), for thermal stress degreases change from $(50)^{\circ} \mathrm{C}$ (untreated sample) to $(36.9 \& 33.6)^{\circ} \mathrm{C}$ for treated samples while martensitic transformation degrees change from $(65)^{\circ} \mathrm{C}$ to $(57.5 \& 51.7)^{\circ} \mathrm{C}$ for treated sample.

\section{ACKNOWLEDGMENT}

The authors would like to thank Dr. Raheem K. Ajeel (Universiti Kebangsaan Malaysia) for his supervision and discussions on experimental work and results in support of the research.

\section{REFERENCES}

[1] ASM. (1998). Properties and Selection Nano Ferrous
Alloy and Special Purpose Materials, 5th edition, Vol. 2. [2] Cismasiu., Corneliu. (2010). Shape Memory Alloys. India.

[3] Melton, K.N. (1998). General applications of SMA and smart materials. Shape memory materials.

[4] Maruyama, T., Kubo, H. (2011). Ferrous (Fe-based) shape memory alloys (SMAs): properties, processing and applications. In Shape Memory and Superelastic Alloys. pp. 141-159. Woodhead Publishing.

[5] Song, G., Ma, N., Li, H.N. (2006). Applications of shape memory alloys in civil structures. Engineering structures, 28(9): https://doi.org/10.1016/j.engstruct.2005.12.010

[6] Addington, D.M., Schodek, D.L. (2005). Smart materials and new technologies: for the architecture and design professions. Routledge. https://doi.org/10.1111/j.1531314X.2005.00018.x

[7] Walker, D.R. (2008). Fabrication and Design of Hybrid Monolithic Shape Memory Alloy Actuators (Master's thesis, University of Waterloo).

[8] Roy, D., Buravalla, V., Mangalgiri, P.D., Allegavi, S., Ramamurty, U. (2008). Mechanical characterization of NiTi SMA wires using a dynamic mechanical analyzer. Materials Science and Engineering: A, 494(1-2): 429435. https://doi.org/10.1016/j.msea.2008.04.052

[9] Cui, Z.D., Man, H.C., Yang, X.J. (2005). The corrosion and nickel release behavior of laser surface-melted NiTi shape memory alloy in Hanks' solution. Surface and Coatings Technology, 192(2-3): 347-353. https://doi.org/10.1016/j.surfcoat.2004.06.033

[10] Madamba, D.L.L. (2013). The effect of surface treatment of Ni leaching from nitinol. Msc thesis, sanjose state university. https://doi.org/10.31979/etd.uyvh-6h8x

[11] Cheng, X., Lowe, S.B., Reece, P.J., Gooding, J.J. (2014). Colloidal silicon quantum dots: from preparation to the modification of self-assembled monolayers (SAMs) for bio-applications. Chemical Society Reviews, 43(8): 2680-2700. https://doi.org/10.1039/C3CS60353A

[12] Man, H.C., Cui, Z.D., Yue, T.M. (2001). Corrosion properties of laser surface melted NiTi shape memory alloy. Scripta Materialia, 45(12): 1447-1453. https://doi.org/10.1016/S1359-6462(01)01182-4

[13] Wang, X., Xia, W., Wu, X., Wei, Y., Huang, C. (2013). Microstructure and mechanical properties of an austenite NiTi shape memory alloy treated with laser induced shock. Materials Science and Engineering: A, 578: 1-5. https://doi.org/10.1016/j.msea.2013.04.058

[14] Yuan, B., Lai, M., Gao, Y., Chung, C.Y., Zhu, M. (2011). The effect of pore characteristics on Ni suppression of porous NiTi shape memory alloys modified by surface treatment. Thin Solid Films, 519(15): 5297-5301. https://doi.org/10.1016/j.tsf.2011.01.114

[15] Hao, L., Lawrence, J. (2005). Laser surface treatment of bio-implant materials. Chichester, UK: Wiley. ISBN: 9780470016879

[16] Man, H.C., Zhao, N.Q. (2006). Phase transformation characteristics of laser gas nitrided NiTi shape memory alloy. Surface and Coatings Technology, 200(18-19): 5598-5605. https://doi.org/10.1016/j.surfcoat.2005.07.079

[17] Ristoscu, C., Mihailescu, I.N. (2013). Biomimetic coatings by pulsed laser deposition. In Laser Technology in Biomimetics, pp. 163-191. ISBN: 978-3-642-41340-7.

[18] Villermaux, F., Tabrizian, M., L'H, Y., Meunier, M., 
Piron, D.L. (1997). Excimer laser treatment of NiTi shape memory alloy biomaterials. Applied Surface Science, 109: 62-66.

[19] Ionescu, A.C., Brambilla, E., Azzola, F., Ottobelli, M., Pellegrini, G., Francetti, L.A. (2018). Laser microtextured titanium implant surfaces reduce in vitro and in situ oral biofilm formation. PloS one, 13(9): e0202262. https://doi.org/10.1371/journal.pone.0202262

[20] Meier, H., Haberland, C., Frenzel, J. (2011). Structural and functional properties of NiTi shape memory alloys produced by selective laser melting. Innovative Developments in Design and Manufacturing: Advanced
Research in Virtual and Rapid Prototyping, pp. 291-296.

[21] Dias, D., Santos, O.S., Alves, W., Lima, M.S.F., Silva, M.M.D. (2019). Fiber laser surface melting of a NiTi Superelastic alloy: Influence on structural and mechanical properties. Metals, 9(12): 1268. https://doi.org/10.3390/met9121268

[22] Lopes, N.I.D.A., Silva, L.Á.D.O., Santos, L.D.A., Buono, V.T.L. (2017). Surface characterization of NiTi superelastic and shape memory alloys after electrolytic polishing. Materials Research, 20: 572-579. http://dx.doi.org/10.1590/1980-5373-mr-2016-0933 